\title{
Comparative Analysis of Three Calculation Models to Simulate Energy Performance of Aerogel Glazing System
}

\author{
Dongmei Zheng ${ }^{1,2}$, Youming Chen ${ }^{1,2}$, Yaling Xiao ${ }^{1,2}$, Yang Liu ${ }^{1,2}$, Yupeng $\mathrm{Li}^{1,2}$, Siqian Zheng ${ }^{1,2}$, \\ $\mathrm{Bin} \mathrm{Lu}^{3}$ \\ ${ }^{1}$ College of Civil Engineering, Hunan University, Changsha, Hunan 410082, China \\ ${ }^{2}$ Key Laboratory of Building Safety and Energy Efficiency of the Ministry of Education, \\ Hunan University, Changsha, Hunan 410082, China \\ ${ }^{3}$ College of Materials Science and Engineering, Central South University, Changsha, Hunan \\ 410083, China
}

\begin{abstract}
Increased attention has been paid to the Aerogel glazing systems (AGS) in recent years, but the light, heat, and solar radiation transfer in the AGS have not been accurately calculated with existing building energy simulation software. In this paper, we introduce the detailed dynamic heat transfer and solar radiation transmission calculation model (the detailed model) of the AGS which had been validated by the experiment. The simplified heat transfer and solar radiation transmission calculation model (the simplified model) of the AGS and the overall heat transfer coefficient $K$ and the shading coefficient $S C$ model (the K-SC model) are given to make a comparison. The meteorological parameters of Changsha are used as the calculation conditions to compare the heat gain calculated by the detailed model, the simplified model and the K-SC model under different climate and orientations. The results show that the total heat gain calculated by the K-SC model and the simplified model is higher than the detailed model. In cooling season, the relative error of the K-SC model range from $18.65 \%$ to $24.46 \%$ and the value of the simplified model range from $8.39 \%$ to $12.17 \%$. In heating season, the relative errors of the K-SC model and the simplified model are at least $61.91 \%$ and $36.86 \%$, respectively. The K-SC model is not suitable to simulate the energy performance of the AGS. Moreover, the simplified model has a bit better accuracy than the K-SC model.
\end{abstract}

\section{Introduction}

As the weakest insulation part of building envelope components, the energy consumption caused by external windows accounts for $40-50 \%$ of total energy consumption through building envelope in China (Feng et al., 2016). Numerous energy efficient technologies have been implemented to reduce energy consumption through windows, such as vacuum glazing, low-e glazing, polycarbonate glazing, electrochromic glazing, etc. (Dussault and \& Gosselin, 2017; Moretti, et al., 2018).

Aerogel glazing systems (AGS) has been attracting increased attention in recent years owing to its excellent thermal insulation performance, high visible transmittance and specific acoustic properties. The overall heat transfer coefficient $K$ can be as low as $1 \mathrm{~W} /\left(\mathrm{m}^{2} \cdot \mathrm{K}\right)$, the light transmittance of aerogel glazing is in the range of 0.3 to 0.6 (Cuce, et al., 2014). AGS is manufactured by densely filling the air interlayer between two or three flat glasses with granular or monolithic aerogel. Due to the fragility of monolithic aerogel, the monolithic aerogel has not been been commercialized at large scale (Berardi, 2015). Therefore, the AGS investigated in this study is the granular one.

The thermal, optical and energy performance of AGS are subjects of study and discussion. Most of the studies evaluated the performances of AGS by simulation tools. Berardi (2015) simulated four designs with different rates of monolithic aerogel replacements in a retrofit project of an educational building at Worcester Polytechnic Institute. Results showed that the heating energy consumption decreased linearly with the increased proportion of aerogel glazing in the windows. Ihara et al. (2015) simulated the energy consumption in an office building with granular silica aerogel glazing systems at spandrels with EnergyPlus. Results showed that aerogel glazing systems are the best candidates in cooling dominated climates such as Tokyo and Singapore. Huang et al. (2015) simulated the energy performance of a silica aerogel glazing system with EnergyPlus. It indicated that the application of AGS can reduce the annual space cooling load by around $4 \%$ for a typical commercial building in Hong Kong. Wang et al. (2013) investigated the feasibility of two newly developed aerogel glazing systems and three common glazing systems in various climate zones of China with eQUEST.

It is concluded that EnergyPlus and eQUEST are the main simulation tools to evaluate the performance of the AGS. The calculation methods are based on the overall heat transfer coefficient $K$ calculated under standard climate conditions and shading coefficient $S C$ value of the normal incidence. However, the overall heat transfer coefficient $K$ and the shading coefficient $S C$ model (the K-SC model) overlook the scattering and absorption phenomena happened in the aerogel layer, which influences the temperature distribution in the AGS. Moreover, the boundary conditions (including the solar incident angle, climate conditions) vary during the year, while the K-SC model is calculated under static conditions. Therefore, the accuracy of the K-SC model evaluating the energy performance of the AGS is still questionable. 
This paper introduce the detailed dynamic heat transfer and solar radiation transmission calculation model (the detailed model) of the AGS which had been validated by the experiment. The simplified heat transfer and solar radiation transmission calculation model (the simplified model) of the AGS is proposed to optimize the calculation speed. The K-SC model is introduced to verify its accuracy. By comparing the heat gain calculated by the detailed model, the simplified model and the K-SC model, the accuracy and feasibility of each model are discussed, which can provide reference and guidance for simulating the energy performance of the AGS.

\section{Three models for AGS}

\section{The detailed model}

The object of this paper is the AGS filled with granular aerogel. Figure 1 illustrates the heat transfer mechanism of the AGS. The heat transfer processes in the AGS involve conduction, convection, and radiation. When the incident solar radiation reaches the outer surface of the AGS, one part of the solar radiation is directly transmitted, another part of the solar radiation is absorbed by aerogel and glass layers of the AGS, resulting in the temperature rise. Heat conduction occurs owing to the temperature differences between each layer. Meanwhile, the convection and long-wave radiation heat transfer happened between the outermost or the innermost surfaces of the AGS and surroundings are considered. The effect of the window frame is overlooked.

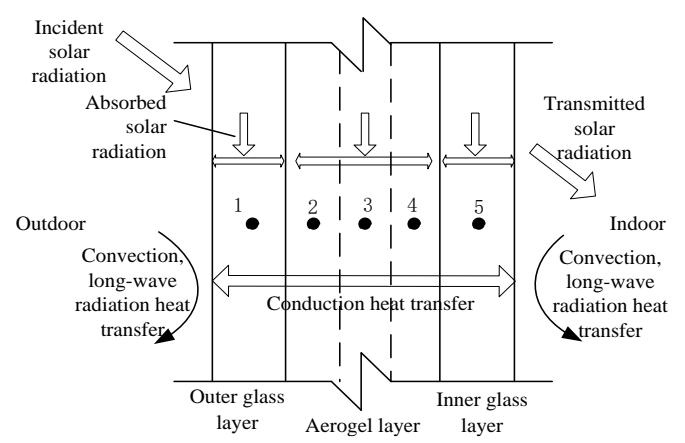

Figure 1: Heat-transfer mechanism of AGS.

The AGS has a three-layer structure, outer glass layer, aerogel layer and inner glass layer. As shown in Figure 1, the vertical AGS is divided into five regions, and each node represent the temperature of the region. The heat flux is considered to be one-dimensional and the solar radiation absorbed by each node in the aerogel layer of the AGS is regarded as averagely distributed. Taking the absorbed solar radiation, the long-wave radiative, the convective and the conductive heat fluxes into account, the energy conservation equations for each node are developed as follows (Chen, 2018).

$$
\begin{gathered}
\rho_{1} c_{\mathrm{p} 1} \delta_{1} \frac{d T_{1}}{d t}=h_{\mathrm{ce}}\left(T_{\mathrm{e}}-T_{1}\right)+h_{\mathrm{re}}\left(T_{\mathrm{e}}-T_{1}\right)+k_{1}\left(T_{2}-T_{1}\right)+q_{\alpha 1} \\
\rho_{2} c_{\mathrm{p} 2} \frac{\delta_{2}}{3} \frac{d T_{2}}{d t}=k_{1}\left(T_{1}-T_{2}\right)+k_{2}\left(T_{3}-T_{2}\right)+\frac{1}{3} q_{\alpha 2}
\end{gathered}
$$

$$
\begin{gathered}
\rho_{2} c_{\mathrm{p} 2} \frac{\delta_{2}}{3} \frac{d T_{3}}{d t}=k_{2}\left(T_{2}-T_{3}\right)+k_{2}\left(T_{4}-T_{3}\right)+\frac{1}{3} q_{\alpha 2} \\
\rho_{2} c_{\mathrm{p} 2} \frac{\delta_{2}}{3} \frac{d T_{4}}{d t}=k_{2}\left(T_{3}-T_{4}\right)+k_{1}\left(T_{5}-T_{4}\right)+\frac{1}{3} q_{\alpha 2} \\
\rho_{1} c_{\mathrm{p} 1} \delta_{1} \frac{d T_{5}}{d t}=h_{\mathrm{ci}}\left(T_{\mathrm{i}}-T_{5}\right)+h_{\mathrm{ri}}\left(T_{\mathrm{i}}-T_{5}\right)+k_{1}\left(T_{4}-T_{5}\right)+q_{\alpha 3}
\end{gathered}
$$

Figure 2 illustrates the solar radiation transmission processes through the AGS. Due to the high porosity of the nanostructured granulate aerogel, a number of the solar radiation are absorbed and scattered by aerogel when the incident solar radiation reaches the aerogel layer. The scattered solar radiation continues to be absorbed and scattered when reaching another granular aerogel. One part of the solar radiation reaching interface 3 is refracted into the inner glass layer. Another part is reflected back to the aerogel layer to repeat the scattering and absorption process described above. Tracing the solar radiation path is very complicated, the interfacial energy balance method is used to calculate the solar radiation transmission performance of the AGS (Chen, 2018).

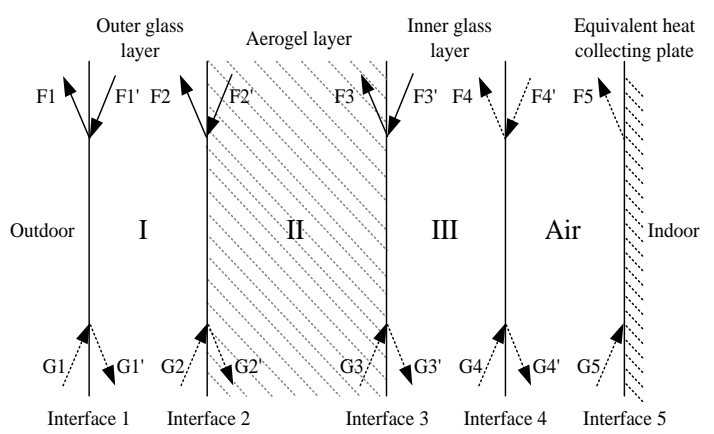

Figure 2: Schematic diagram of the transmitting system.

The interfacial energy balance equation at Interface $m$ can be presented as Eq. (6).

$$
G_{m}+F_{m}{ }^{\prime}=F_{m}+G_{m}{ }^{\prime}
$$

Due to the complicated solar radiation path in the aerogel layer, it is considered that the incident diffuse irradiance on the inner glass layer through the interface 3 is isotropic. The transmitted solar irradiance from interface 3 to 4 is calculated by averaging the respective transmitted direct irradiance over all the directions. The transmittance of the inner glass layer is calculated by Eq. (7) (Liu, 2017).

$$
\tau_{3 \rightarrow 4}=\frac{2 \int_{0}^{90^{\circ}} \tau_{3 \rightarrow 4}(\theta) I_{3} d \theta}{2 \int_{0}^{90^{\circ}} I_{3} d \theta}=\frac{2}{\pi} \int_{0}^{90^{\circ}} \tau_{3 \rightarrow 4}(\theta) d \theta
$$

The total transmittance of the AGS and the absorptance of each layer of the AGS is calculated by the following two equations, respectively.

$$
\tau=\prod_{m=1}^{4}\left(\varphi_{m} \tau_{m \rightarrow m+1}\right)
$$




$$
\alpha_{m \rightarrow m+1}=\varphi_{m}\left(1-\tau_{m \rightarrow m+1}+\beta_{m}^{\prime} \frac{1-\tau_{m \rightarrow m+1}}{\tau_{m \rightarrow m+1}}\right) \prod_{m=1}^{4} \varphi_{m} \tau_{m \rightarrow m+1}
$$

For the direct irradiance, the transmittance of the AGS and the absorptance of each layer of the AGS can be calculated after obtaining the solar incident angle of the AGS. Assuming the diffuse irradiance is isotropic, the transmittance of AGS and the absorptance of each layer of the AGS can be calculated by integrating the direct solar incident angle from $0^{\circ} \sim 90^{\circ}$.

$$
\tau_{\mathrm{d}}=\frac{2 \int_{0}^{90^{\circ}} \tau_{\mathrm{D}}(\theta) I d \theta}{2 \int_{0}^{90^{\circ}} I d \theta}=\frac{2}{\pi} \int_{0}^{90^{\circ}} \tau_{\mathrm{D}}(\theta) d \theta
$$

The overall absorptance and transmittance of the AGS are calculated by Eq. (11) and Eq. (12), respectively.

$$
\begin{gathered}
\alpha=\frac{\alpha_{\mathrm{D}} I_{\mathrm{D}}+\alpha_{\mathrm{d}} I_{\mathrm{d}}}{I} \\
\tau=\frac{\tau_{\mathrm{D}} I_{\mathrm{D}}+\tau_{\mathrm{d}} I_{\mathrm{d}}}{I}
\end{gathered}
$$

The total heat gain reflect the energy performance of the AGS.The hourly total heat gain by unit area of the AGS are composed of a solar radiation related component $\left(q_{\text {solar }}\right)$ and a temperature related component $\left(q_{\text {temp }}\right)$, which are calculated by Eq. (13). The temperature related component $\left(q_{\text {temp }}\right)$ is the heat flow into room side due to the temperature difference between the inner surface of AGS and the indoor air (Zhang, 2016).

$$
q=q_{\mathrm{solar}}+q_{\mathrm{temp}}=\tau I+\left[h_{\mathrm{ci}}\left(T_{5}-T_{\mathrm{i}}\right)+h_{\mathrm{ri}}\left(T_{5}-T_{\mathrm{i}}\right)\right]
$$

An experiment was performed with an AGS installed horizontally to validate the detailed model of the AGS. The experimental platform was built on the roof of a building at Hunan University located in Changsha, China $(112.9 \mathrm{E}, 28.22 \mathrm{~N})$. The averaged relative error of the indoor solar heat gain in the daytime on June 20th and 21 st is $2.1 \%$ and $5.6 \%$, respectively. The root mean square error of the simulated and measured result for the temperatures of the inner glass layer is $1.1{ }^{\circ} \mathrm{C}$. The measured results and the simulated results of the detailed model have a good agreement. The details on the detailed model and the experimental verification are available in Chen (2018).

\section{The simplified model}

To make the detailed model as fast and as easy as possible, the simplified model of the AGS are proposed. Due to the complicated solar radiation path in the aerogel layer, the Eq. (7) is complex with a large amount of calculation. The simplified model is considered to overlook the scattering and absorption phenomena happened in the aerogel layer. The transmittance of the inner glass layer is calculated by the Bouguer-Beer law.

$$
\tau_{m \rightarrow m+1}=\exp \left(-k_{\mathrm{e}} L\right)
$$

For the diffuse irradiance, the total transmittance of the AGS and the absorptance of each glass layer of the AGS is simplified by calculating the values of the direct irradiance in the $60^{\circ}$ solar incident angle (Zanghirella, 2009).

It is assumed that the temperature differences between the aerogel layer and the indoor or outdoor environment is equal. The absorbed solar radiation by aerogel layer is considered to be averagely distributed according to the thermal resistance ratio. The indoor heat gain include 5 components: the conductive heat gain, the transmitted solar radiation, the heat gain transferred from the outer glass, inner glass and aerogel layers after absorbing the solar radiation. It is calculated by the follow equation.

$$
q=K\left(T_{\mathrm{e}}-T_{\mathrm{i}}\right)+\sum_{\mathrm{n}=1}^{3} \frac{\alpha_{m \rightarrow m+1} \cdot R_{\text {out }, \mathrm{n}}}{R_{\text {total }}} I+\tau I
$$

The overall heat transfer coefficient $K$ is calculated by the follow equation:

$$
K=\left(\frac{1}{h_{\mathrm{ce}}+h_{\mathrm{re}}}+\sum_{n=1}^{3} \frac{\delta_{n}}{\lambda_{n}}+\frac{1}{h_{\mathrm{ci}}+h_{\mathrm{ri}}}\right)^{-1}
$$

The convective heat transfer coefficient and the radiative heat transfer coefficient are available in the Ministry of Housing and Urban-Rural Development of the People's Republic of China (2008).

\section{The K-SC model}

The K-SC model is a simplified model commonly used in the computation of glass. The heat gain caused by the AGS is divided into two parts: one is the conductive heat gain caused by the indoor and outdoor temperature differences; another is the heat gain caused by the solar radiation, which consists of the transmitted solar radiation and the "secondary heat gain" transferring to the room after absorbing the solar radiation by the AGS. The total heat gain is calculated by the follow equation. (Ministry of Housing and Urban-Rural Development of the People's Republic of China, 2008)

$$
q=K\left(T_{\mathrm{e}}-T_{\mathrm{i}}\right)+S H G C \cdot I
$$

The solar heat gain coefficient of the direct radiation $S H G C_{\mathrm{D}}$ takes the calculated value of the normal incidence. The solar heat gain coefficient of the diffuse radiation $S H G C_{\mathrm{d}}$ takes the calculated value of the direct radiation with the solar incident angle of $60^{\circ}$.

$$
q=K\left(T_{\mathrm{e}}-T_{\mathrm{i}}\right)+S H G C_{\mathrm{D}} \cdot I_{\mathrm{D}}+S H G C_{\mathrm{d}} \cdot I_{\mathrm{d}}
$$

The calculated $K$ of the AGS ( $8 \mathrm{~mm}$ clear glass $+12 \mathrm{~mm}$ granular silica aerogel+8 $\mathrm{mm}$ clear glass) is 1.44 $\mathrm{W} /\left(\mathrm{m}^{2} \cdot \mathrm{K}\right)$, the $S H G C_{\mathrm{D}}$ is 0.64 , the $S H G C_{\mathrm{d}}$ is 0.49 .

\section{Comparisons for three models}

There are two main types of heat gain entering the room through the AGS: one is the heat gain generated by the transmitted solar radiation; another is the heat gain caused by the temperature differences between the inner surface of the inner glass and the room (including convection heat transfer and long wave radiation heat transfer). The heat 
gain of the AGS installed horizontally in Changsha on July 21 st is calculated by the detailed model, the simplified model and the K-SC model. Figure 3 shows the Meteorological data of July 21 st. The outdoor conditions (outdoor air temperature, the global horizontal irradiance, the diffuse horizontal irradiance and the direct normal irradiance) are taken from typical meteorological year data (China Meteorological Bureau, et al., 2005). The indoor temperature is set as $25^{\circ} \mathrm{C}$. The total thickness of the AGS calculated in this study is $28 \mathrm{~mm}$, where the glasses are both $8 \mathrm{~mm}$ and the aerogel layer is $12 \mathrm{~mm}$. The physical property parameter of the AGS is listed in Table 1.

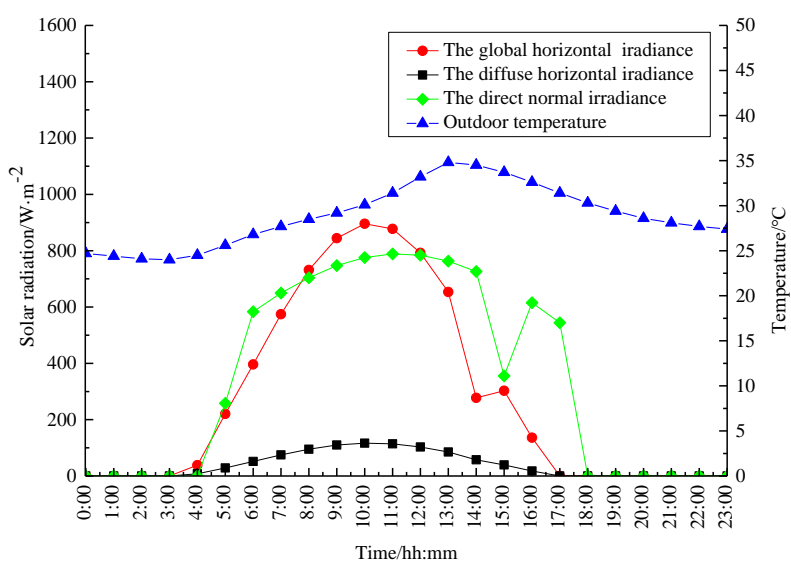

Figure 3: Meteorological data of July 21st in Changsha.

Table 1: Physical property parameter.

\begin{tabular}{|c|c|c|}
\hline Physical properties & $\begin{array}{c}\text { Clear } \\
\text { glass }\end{array}$ & $\begin{array}{c}\text { Silica } \\
\text { aerogel }\end{array}$ \\
\hline Density $/ \mathrm{kg} \cdot \mathrm{m}^{-3}$ & 2500 & 100 \\
\hline Heat capacity $\mathrm{J} \cdot(\mathrm{kg} \cdot \mathrm{K})^{-1}$ & 840 & 3500 \\
\hline Thermal conductivity $/ \mathrm{W} \cdot(\mathrm{m} \cdot \mathrm{K})^{-1}$ & 0.75 & 0.024 \\
\hline Extinction coefficient $/ \mathrm{mm}^{-1}$ & 0.016 & 0.0296 \\
\hline Refractive index & 1.526 & 1.02 \\
\hline
\end{tabular}

The differences between the heat gain calculated by three models are discussed in this chapter. The relative error $R E$ is used to quantitatively describe the calculation differences of the heat gain between the K-SC model, the simplified model and the detailed model which had been validated by the experiment.

$$
R E=\frac{\left|Q_{C}-Q_{T}\right|}{Q_{T}}
$$

where $R E$ is the relative deviation (\%); $Q_{\mathrm{C}}$ is the heat gain calculated by the K-SC model or the simplified model $\left(\mathrm{W} / \mathrm{m}^{2}\right) ; Q_{\mathrm{T}}$ is the heat gain calculated by the detailed model $\left(\mathrm{W} / \mathrm{m}^{2}\right)$.

\section{The transmitted solar heat gain}

The transmitted solar heat gain calculated by three models is shown in Figure 4. It is observed that the curves of the transmitted solar heat gain calculated by three models have similar trends, but the value calculated by the simplified model and the K-SC model in the daytime is larger than the detailed model. The solar radiation path are significantly shortened by overlooking the absorption and scattering phenomena happened in the aerogel, making more transmitted solar heat gain calculated by the simplified model and the K-SC model. Moreover, the transmitted solar heat gain is calculated in the normal incidence in the $\mathrm{K}-\mathrm{SC}$ model, resulting in larger solar radiation transmitted into room. It is found that the transmitted solar heat gain calculated by the K-SC model has large error than the simplified model at 5:00 AM to 9:00 AM. That is caused by the constant solar incident angle settled in the K-SC model, while the solar incident angle is changing with the time and it is significantly larger than the settled solar incident angle in the K-SC model in the morning. Since the solar incident angle approaches $0^{\circ}$ at noon, the differences between the K-SC model and the simplified model is less significant at noon. The cumulative transmitted solar heat gain calculated by the $\mathrm{K}-\mathrm{SC}$ model is higher than the detailed model by $54.96 \%$ on July 21 st, the relative error of the simplified model is $28.21 \%$.

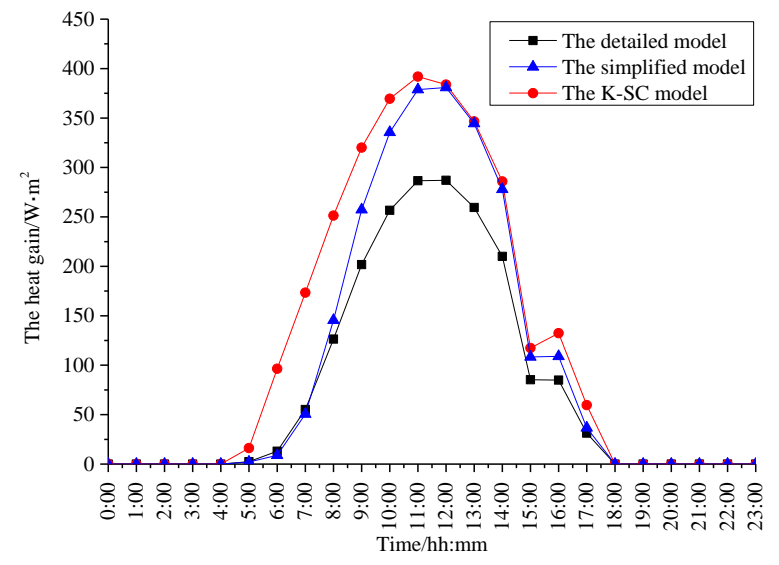

Figure 4: The transmitted solar heat gain on July 21 st.

\section{The heat gain caused by the temperature differences}

The calculated heat gain caused by the temperature differences of three models is shown in Figure 5. The aerogel has a large density and specific heat, and the heat storage of the aerogel cannot be overlooked. The temperature of the aerogel layer rise remarkably after the absorption of the incident solar radiation, meanwhile the inner glass temperature is generally lower than the outer glass temperature in summer, therefore a larger part of the solar radiation absorbed by the aerogel layer is transmitted to the room than the outside. However the simplified model and the K-SC model are considered that the temperature differences between each glass layer and the inner and outer surfaces of the AGS is equal, contributing to smaller calculated heat gain caused by the temperature differences of the simplified model and the $\mathrm{K}-\mathrm{SC}$ model. It is found that the value calculated by the $\mathrm{K}-\mathrm{SC}$ model at 5:00 AM to 6:00 AM is higher than the other two models. The reflectance of the simplified model and the detailed model is high when the solar incident angle approach $90^{\circ}$. Therefore, there are little solar radiation absorbed by the aerogel and transferring into the room in the simplified model and the detailed model at 5:00 AM to 6:00 AM. 
In the night, the value calculated by the simplified model and the K-SC model are higher than the detailed model. The sky temperature in the night is lower than the air temperature, resulting in a large amount of radiative heat loss between the outer glass and the outdoor environment. The effect is considered in the detailed model, therefore the value calculated by the detailed model is lower. The cumulative calculated heat gain caused by the temperature differences of the K-SC model is lower than that of the detailed model by $8.93 \%$ on July $21 \mathrm{st}$, the relative error of the simplified model is $4.41 \%$.

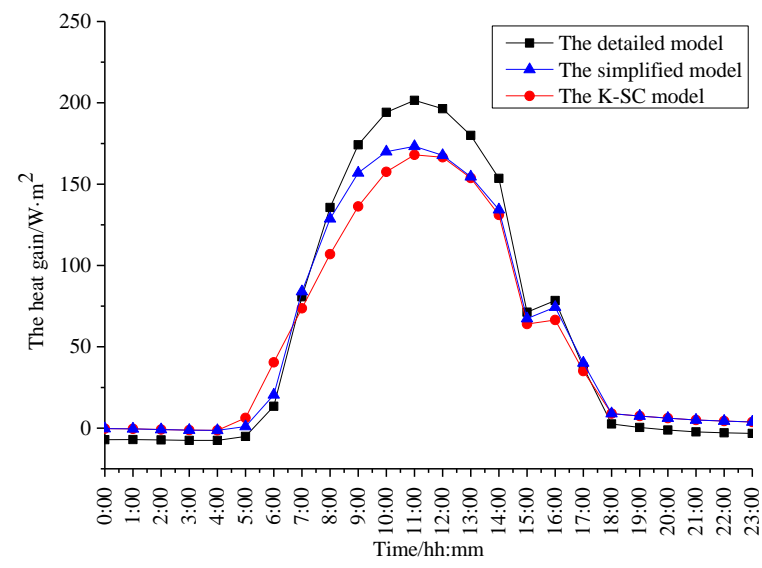

Figure 5: The heat gain caused by the temperature differences on July 21 st.

\section{The daily total heat gain}

It is concluded from Figure 4 and Figure 5 that the transmitted heat gain is dominated in the daytime. The transmitted solar heat gain calculated by the K-SC model and the simplified model is higher than the detailed model, contributing to higher total heat gain calculated by the KSC model and the simplified model. In the night, the heat gain caused by the temperature differences is the main component of the total heat gain, therefore the total heat gain calculated by the K-SC model and the simplified model are higher than the detailed model in the night. As shown in Figure 6, the relative error of the simplified model is large at noon when the solar radiation is strong. In addition, the relative error of the K-SC model in the daytime is almost higher than the simplified model. The daily total heat gain calculated by the K-SC model is higher than the detailed model by $27.11 \%$ on July 21 st, the relative error of the simplified model is $13.99 \%$.

In order to analyze the accuracy of the K-SC model and the simplified model in different orientations, the daily total heat gain calculated by three models in the east, south, west, north orientations is shown in Figure 7. It is found that the relative error of the simplified model is large in the morning in the east and in the afternoon in the west when the solar radiation is strong. Due to the lower solar radiation in the south and north, the accuracy of the simplified model is good. However, the relative error of the $\mathrm{K}-\mathrm{SC}$ model is large in the daytime in every orientation, especially in south and north. The solar incident angle settled in the K-SC model is $0^{\circ}$, while the actual hourly incident solar angle is almost $90^{\circ}$ in south. Therefore, the relative error of the K-SC model is up to $41.31 \%$ at 12:00 AM in the south. The relative errors of the daily total heat gain calculated by the K-SC model and the simplified model are listed in Table 2. The relative error of the K-SC model range from $22.91 \%$ to $46.34 \%$, the relative error of the simplified model is lower than $15 \%$. The accuracy of the simplified model is a bit better than the K-SC model. For the simplified model, the relative error in the north is the smallest with a value of $11.86 \%$.

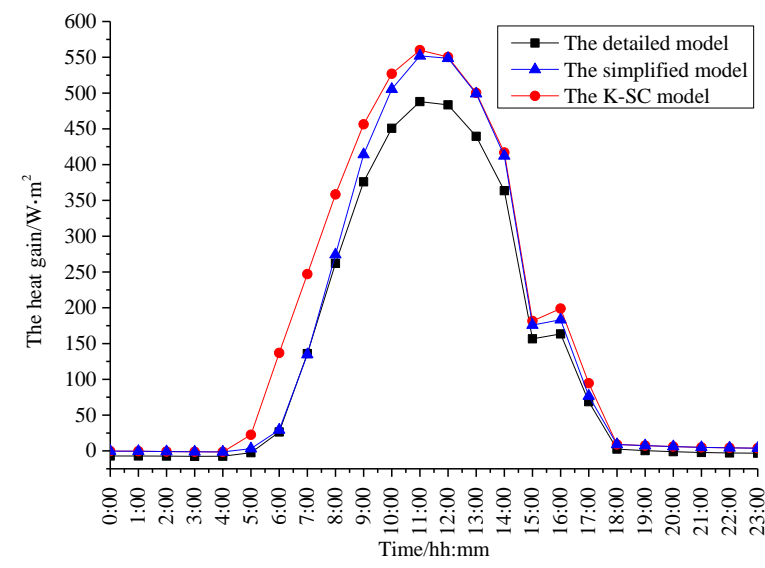

Figure 6: The daily total heat gain on July 21st.
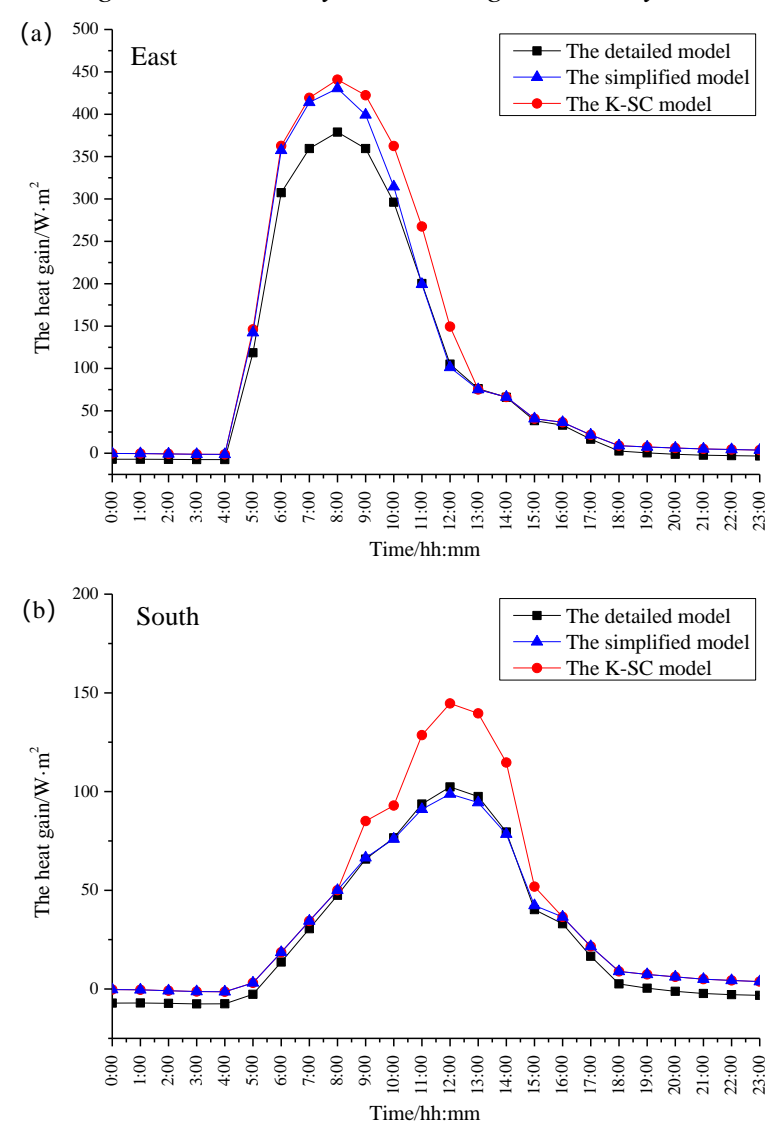

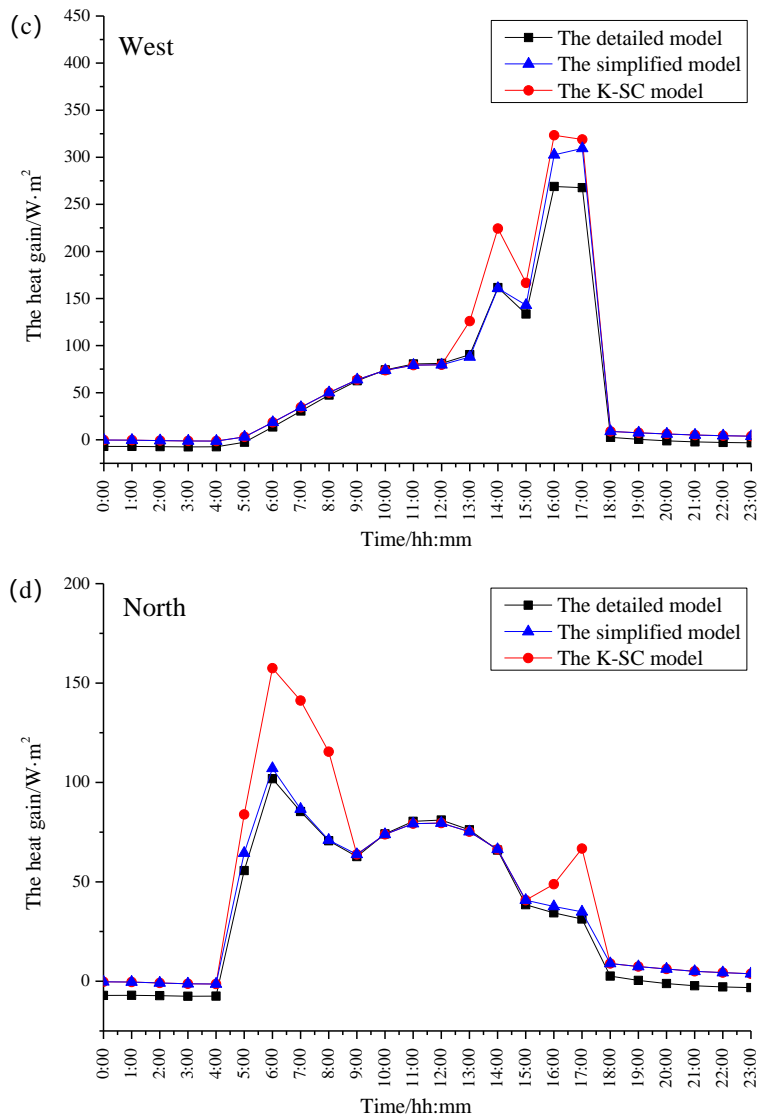

Figure 7: The daily total heat gain in different orientation: (a) east, (b) south, $(c)$ west, $(d)$ north on July 21 st.

Table 2: The RE of the K-SC model and the simplified model.

\begin{tabular}{|c|c|c|}
\hline \multirow{2}{*}{ Orientation } & \multicolumn{2}{|c|}{$\boldsymbol{R E}$ / \% } \\
\cline { 2 - 3 } & The K-SC model & The simplified model \\
\hline East & 22.91 & 13.74 \\
\hline South & 46.34 & 14.10 \\
\hline West & 25.79 & 13.53 \\
\hline North & 37.84 & 11.86 \\
\hline Horizontal & 27.11 & 13.99 \\
\hline
\end{tabular}

\section{The total heat gain in cooling and heating} seasons

In order to compare the differences between three models for simulating the energy performance of the AGS, the total heat gain of the AGS in cooling and heating seasons in each direction is calculated. The typical meteorological year data of Changsha is used as the calculation condition (China Meteorological Bureau, et al., 2005). Changsha is the typical city in hot summer and cold winter zone, the heating season is from November 12th to April 10th, the cooling season is from June 25th to August 23rd. The design temperature in the cooling and heating season is $25^{\circ} \mathrm{C}$ and $20{ }^{\circ} \mathrm{C}$, respectively.

Table 3 shows the total heat gain in cooling and heating seasons calculated by three models. The relative error of the K-SC model range from $18.65 \%$ to $24.46 \%$ in cooling season, the energy saving potential of the AGS will be underestimated. The relative error of the K-SC model in the north is the largest because of the huge differences of the solar incident angle between the K-SC model and the detailed model. The relative error of the simplified model range from $8.39 \%$ to $12.17 \%$ in cooling season, which is lower than the K-SC model. The relative error of the simplified model in the north is the smallest. That is caused by the lower solar radiation in the north.

The energy saving potential of the AGS will be overestimated in heating season because of the higher heat gain calculated by the K-SC model and the simplified model. The relative error of the K-SC model is more than $61.91 \%$ in heating season. The relative error of the simplified model is more than $36.86 \%$ in heating season, which is lower than the K-SC model. The largest differences between the K-SC model and the simplified model is the method in calculating the optical parameters of the direct radiation, while there is little direct radiation in the north. Therefore, the relative errors between the K$\mathrm{SC}$ model and the simplified model in the north are almost equal. The relative errors of the K-SC model and the simplified model in the west are both the largest. The total heat loss calculated by the detailed model is $7.65 \mathrm{kWh} / \mathrm{m}^{2}$ in the west, while the total heat gain calculated by the K$\mathrm{SC}$ model and the simplified model is $13.76 \mathrm{kWh} / \mathrm{m}^{2}$ and $10.68 \mathrm{kWh} / \mathrm{m}^{2}$, respectively.

It is concluded that the total heat gain calculated by the $\mathrm{K}$ SC model and the simplified model is higher than the detailed model. The energy saving potential of the AGS is underestimated in cooling season and overestimated in heating season, which adversely affect the promotion and application of the AGS. While the relative error of the simplified model is lower than the K-SC model.

Table 3: The total heat gain in cooling and heating seasons.

\begin{tabular}{|c|c|c|c|c|c|c|c|c|c|c|}
\hline \multirow[t]{2}{*}{ Orientation } & \multicolumn{5}{|c|}{ The total heat gain in cooling season/ $\mathrm{kWh} \cdot \mathrm{m}^{-2}$} & \multicolumn{5}{|c|}{ The total heat gain in heating season/ $\mathrm{kWh} \cdot \mathrm{m}^{-2}$} \\
\hline & $\begin{array}{c}\text { The } \\
\text { detailed } \\
\text { model }\end{array}$ & $\begin{array}{c}\text { The } \\
\text { K-SC } \\
\text { model } \\
\end{array}$ & $R E / \%$ & $\begin{array}{c}\text { The } \\
\text { simplified } \\
\text { model }\end{array}$ & $R E / \%$ & $\begin{array}{c}\text { The } \\
\text { detailed } \\
\text { model }\end{array}$ & $\begin{array}{c}\text { The } \\
\text { K-SC } \\
\text { model } \\
\end{array}$ & $R E / \%$ & $\begin{array}{c}\text { The } \\
\text { simplified } \\
\text { model }\end{array}$ & $R E / \%$ \\
\hline East & 99.41 & 117.95 & 18.65 & 111.51 & 12.17 & 16.15 & 42.55 & 163.54 & 37.77 & 133.93 \\
\hline South & 45.33 & 56.10 & 23.76 & 49.86 & 10.01 & 25.26 & 55.99 & 121.64 & 46.78 & 85.21 \\
\hline West & 67.21 & 79.97 & 18.99 & 74.60 & 9.91 & -7.65 & 13.76 & -279.81 & 10.68 & -239.60 \\
\hline North & 51.76 & 64.42 & 24.46 & 56.50 & 8.39 & -18.52 & -1.04 & 94.41 & -1.14 & 93.86 \\
\hline Horizontal & 145.06 & 175.14 & 20.74 & 160.59 & 10.70 & 51.08 & 82.71 & 61.91 & 69.91 & 36.86 \\
\hline
\end{tabular}




\section{Conclusion}

In order to provide reference and guidance for simulating the energy performance of AGS, the detailed model, the simplified model and the K-SC model are introduced. The daily total heat gain and the total heat gain in cooling and heating seasons in Changsha calculated by three models are compared. The conclusions are drawn as follows:

(1) The transmitted solar heat gain is dominated in the daily total heat gain in the daytime. In the night, the heat gain caused by temperature differences is the main component of the daily total heat gain.

(2) In cooling season, the relative error of the K-SC model range from $18.65 \%$ to $24.46 \%$ and the relative error of the simplified model range from $8.39 \%$ to $12.17 \%$, which underestimate the energy saving potential of the AGS.

(3) In heating season, the relative error of the K-SC model is more than $61.91 \%$ and the relative error of

\section{Nomenclature}

\begin{tabular}{|llll|}
\hline$c_{p 1} c_{p 2}$ & heat capacity of glass and aerogel $(\mathrm{J} /(\mathrm{kg} \cdot \mathrm{K}))$ & \multicolumn{2}{l|}{ Greek letters } \\
$h_{\mathrm{c}}$ & convective heat transfer coefficient $\left(\mathrm{W} /\left(\mathrm{m}^{2} \cdot \mathrm{K}\right)\right)$ & $\alpha$ & absorptance \\
$h_{\mathrm{r}}$ & radiative heat transfer coefficient $\left(\mathrm{W} /\left(\mathrm{m}^{2} \cdot \mathrm{K}\right)\right)$ & $\tau$ & transmittance \\
$I$ & incident solar radiation $\left(\mathrm{W} / \mathrm{m}^{2}\right)$ & $\delta_{1}, \delta_{2}$ & thickness of glass and aerogel $(\mathrm{m})$ \\
$k_{e}$ & extinction coefficient $\left(\mathrm{mm}^{-1}\right)$ & $\rho_{1} 、 \rho_{2}$ & density of glass and aerogel $\left(\mathrm{kg} / \mathrm{m}^{3}\right)$ \\
$L$ & optical path $(\mathrm{mm})$ & $\varphi$ & front equivalent transmittance \\
$q$ & hourly indoor heat gain $\left(\mathrm{W} / \mathrm{m}^{2}\right)$ & $\beta^{\prime}$ & reciprocal of the back equivalent reflectance \\
$q_{\alpha 1}$ & absorption heat of outer glass layer $\left(\mathrm{W} / \mathrm{m}^{2}\right)$ & $\lambda$ & thermal conductivity $(\mathrm{W} / \mathrm{m} \cdot \mathrm{K})$ \\
$q_{\alpha 2}$ & absorption heat of aerogel layer $\left(\mathrm{W} / \mathrm{m}^{2}\right)$ & Subscripts & \\
$q_{\alpha 3}$ & absorption heat of inner glass layer $\left(\mathrm{W} / \mathrm{m}^{2}\right)$ & $\mathrm{e}$ & outdoor environment \\
$T$ & temperature $(\mathrm{K})$ & $\mathrm{i}$ & indoor environment \\
$t$ & time $(\mathrm{s})$ & $\mathrm{D}$ & direct radiation \\
$k_{1}$ & conductive heat transfer coefficients between & $\mathrm{d}$ & diffuse radiation \\
& aerogel and glass $\left(\mathrm{W} /\left(\mathrm{m}^{2} \cdot \mathrm{K}\right)\right)$ & & \\
$k_{2}$ & conductive heat transfer coefficients of aerogel & $j$ & node number $(j=1 \sim 5)$ \\
$R_{\text {total }}$ & $\left(\mathrm{W} /\left(\mathrm{m}^{2} \cdot \mathrm{K}\right)\right)$ & & Interface number $(m=1 \sim 5)$ \\
$R_{\text {out }}$ & total thermal resistance $\left(\mathrm{m}^{2} \cdot \mathrm{K} / \mathrm{W}\right)$ & $m$ & Layer number $(n=1 \sim 3)$ \\
$K$ & outer thermal resistance $\left(\mathrm{m}^{2} \cdot \mathrm{K} / \mathrm{W}\right)$ & $n$ & \\
\hline & the overall heat transfer coefficient $\left(\mathrm{W} /\left(\mathrm{m}^{2} \cdot \mathrm{K}\right)\right)$ & &
\end{tabular}

\section{References}

Berardi, U. (2015). Development of glazing systems with silica aerogel. Energy Procedia, 78, 394-399.

Berardi, U. (2015). The development of a monolithic aerogel glazed window for an energy retrofitting project. Applied Energy, 154, 603-615.

Chen, Y., Xiao, Y., Zheng, S., et al. (2018). Dynamic heat transfer model and applicability evaluation of aerogel glazing system in various climates of China. Energy, 163, 1115-1124.

Cuce, E., Cuce, P. M., Wood, C. J., et al. (2014). Toward aerogel based thermal superinsulation in buildings: a comprehensive review. Renewable and Sustainable Energy Reviews, 34, 273-299. the simplified model is more than $36.86 \%$, which overestimate the energy saving potential of the AGS.

(4) The K-SC model is not suitable to simulate the energy performance of the AGS. The simplified model has a bit better accuracy than the K-SC model.

(5) Considering the scattering and absorption phenomena happened in the aerogel layer and the changeable solar incident angle with time, the detailed model has better accuracy to simulate the energy performance of the AGS.

\section{Acknowledgement}

The authors would like to express their gratitude to the National Natural Science Foundation of China (Grant no. 51678227) and the "13th Five-Year" National Key R\&D Project of China (Grant no. 2017YFC0702201) for the financial support.
China Meteorological Bureau, Climate Information Center, Climate Data Office and Tsinghua University, Department of Building Science and Technology. (2005). China Standard Weather Data for Analyzing Building Thermal Conditions. China Architecture and Building Press. Beijing (China).(in Chinese)

Dussault, J. M., \& Gosselin, L. (2017). Office buildings with electrochromic windows: a sensitivity analysis of design parameters on energy performance, and thermal and visual comfort. Energy \& Buildings, 153, $50-62$.

Feng, W., Zou L., Gao G., et al. (2016). Gasochromic smart window: optical and thermal properties, energy simulation and feasibility analysis. Solar Energy Materials \& Solar Cells, 144, 316-323. 
Huang, Y., \& Niu, J. (2015). Energy and visual performance of the silica aerogel glazing system in commercial buildings of Hong Kong. Construction \& Building Materials, 94, 57-72.

Ihara, T., Gao, T., Grynning, S., Jelle, B. P., \& Gustavsen, A. (2015). Aerogel granulate glazing facades and their application potential from an energy saving perspective. Applied Energy, 142, 179-191.

Liu, Y., Chen, Y., Li, Y., et al. Solar extinction coefficient of silica aerogel calculated through integral model and experimental data. Proceedings from ISHVAC 2017: 10th international symposium on heating, ventilation and air conditioning. Jinan (China), 19-22 October 2017.

Moretti, E., Zinzi, M., Merli, F., et al. (2018). Optical, thermal, and energy performance of advanced polycarbonate systems with granular aerogel. Energy and Buildings, 166, 407-417.

Ministry of Housing and Urban-Rural Development of the People's Republic of China (2008). Calculation specification for thermal performance of windows, doors and building glass curtain walls (JGJ/T1512008). (in Chinese)

Wang, H., Wu, H., Ding, Y., Zhou, X. Evaluation and optimization of sun-shading performance for aerogel glass in hot summer and warm winter zone. Proceedings from the APEC conference on lowcarbon towns and physical energy storage. Changsha (China), 25-26 May 2013.

Zanghirella, F., Perino, M., \& Serra, V. (2009). A numerical model to evaluate the thermal behaviour of active transparent façades. Energy \& Buildings, 43(5), 1123-1138.

Zhang, C., Wang, J., Xu, X., et al. (2016). Modeling and thermal performance evaluation of a switchable triple glazing exhaust air window. Applied Thermal Engineering, 92, 8-17. 